human reproduction

\title{
Effect of air quality on assisted human reproduction ${ }^{\dagger}$
}

\author{
Richard S. Legro I,", Mark V. Sauer², Gilbert L. Mottla ${ }^{3}$, \\ Kevin S. Richter ${ }^{3}, \mathrm{Xian}_{\mathrm{Li}^{4}}$, William C. Dodson', and Duanping Liao ${ }^{4}$
}

'Department of Obstetrics and Gynecology, Pennsylvania State University College of Medicine, 500 University Drive, HI03, Hershey, PA 17033, USA ${ }^{2}$ Department of Obstetrics and Gynecology, Columbia University College of Physicians and Surgeons, New York, NY 10032, USA ${ }^{3}$ Shady Grove Fertility, Rockville, MD 20850, USA ${ }^{4}$ Department of Public Health Sciences, Pennsylvania State University College of Medicine, Hershey, PA 17033, USA

*Correspondence address. Tel: + I-717-53I-8478; Fax: + I-7|7-53I-6286; E-mail: rsl @@psu.edu

Submitted on September I, 2009; resubmitted on December 21, 2009; accepted on January 10, 2010

\begin{abstract}
BACKGROUND: Air pollution has been associated with reproductive complications. We hypothesized that declining air quality during in vitro fertilization (IVF) would adversely affect live birth rates.
\end{abstract}

METHODS: Data from US Environmental Protection Agency air quality monitors and an established national-scale, log-normal kriging method were used to spatially estimate daily mean concentrations of criteria pollutants at addresses of 7403 females undergoing their first IVF cycle and at the their IVF labs from 2000 to 2007 in the Northeastern USA. These data were related to pregnancy outcomes.

RESULTS: Increases in nitrogen dioxide $\left(\mathrm{NO}_{2}\right)$ concentration both at the patient's address and at the IVF lab were significantly associated with a lower chance of pregnancy and live birth during all phases of an IVF cycle from medication start to pregnancy test [most significantly after embryo transfer, odds ratio (OR) $0.76,95 \%$ confidence interval $(\mathrm{Cl}) 0.66-0.86$, per 0.01 ppm increase]. Increasing ozone $\left(\mathrm{O}_{3}\right)$ concentration at the patient's address was significantly associated with an increased chance of live birth during ovulation induction (OR I.26, 95\% Cl I.10-1.44, per 0.02 ppm increase), but with decreased odds of live birth when exposed from embryo transfer to live birth (OR 0.62 , $95 \%$ $\mathrm{Cl} 0.48-0.8 \mathrm{I}$, per $0.02 \mathrm{ppm}$ increase). After modeling for interactions of $\mathrm{NO}_{2}$ and $\mathrm{O}_{3}$ at the IVF lab, $\mathrm{NO}_{2}$ remained negatively and significantly associated with live birth (OR $0.86,95 \% \mathrm{Cl} 0.78-0.96$ ), whereas $\mathrm{O}_{3}$ was non-significant. Fine particulate matter ( $\mathrm{PM} \mathrm{M}_{2.5}$ ) at the IVF lab during embryo culture was associated with decreased conception rates (OR 0.90, $95 \% \mathrm{Cl} 0.82-0.99$, per $8 \mu \mathrm{g} / \mathrm{m}^{3}$ increase), but not with live birth rates. No associations were noted with sulfur dioxide or larger particulate matter $\left(\mathrm{PM}_{10}\right)$.

CONCLUSIONS: The effects of declining air quality on reproductive outcomes after IVF are variable, cycle-dependent and complex, though increased $\mathrm{NO}_{2}$ is consistently associated with lower live birth rates. Our findings are limited by the lack of direct measure of pollutants at homes and lab sites.

Key words: pollution / ozone / pregnancy / particulate matter / in vitro fertilization

\section{Introduction}

Ambient air pollution has been associated with a wide range of effects on human health, including measurable decrements in lung function (Pope et al., 1991), increases in respiratory symptoms and diseases (Peters et al., 1999) and mortality, primarily from cardiopulmonary causes (Goldberg et al., 200I; Wellenius et al., 2005, 2006; Ostro et al., 2006). Although there is ample literature from animal or human studies looking at surrogate reproductive outcomes, surprisingly little has been published on the effects of air quality on the critical outcome of human reproduction, i.e. live birth (Boone et al., 1999; Sram et al., 2005; Hackley et al., 2007). There does, however, appear to be a causal relationship between air pollution and impaired reproduction in humans, including low birthweight and birth defects (Ritz et al., 2007).

Data from human studies suggest that exposure to pollutants in early- to mid-pregnancy is associated with low birthweight (Lee et al., 2003) which has been attributed to the increased vulnerability of the fetus due to its physiologic immaturity (Sram et al., 2005). An embryo is even more vulnerable, especially outside its relatively sheltered uterine environment as occurs with assisted reproduction. The adverse effects of air quality on human reproduction are perhaps best illustrated by the link between smoking and infertility, pregnancy loss and increased maternal and fetal complications during pregnancy

tThe results are to be presented as an oral presentation at the 65th Annual Meeting of the American Society of Reproductive Medicine in Atlanta GA, 20 October 2009.

(C) The Author 2010. Published by Oxford University Press on behalf of the European Society of Human Reproduction and Embryology. All rights reserved.

For Permissions, please email: journals.permissions@oxfordjournals.org 
(Anonymous, 2008). Results of a meta-analysis examining the outcome of assisted reproduction indicate that smokers require twice the number of IVF attempts to conceive as non-smokers (Feichtinger et al., 1997). The data suggest that a preconception exposure can be harmful to pregnancy.

Short-term exacerbations in air quality have been associated with an increased frequency of cardiovascular events through unknown mechanisms. The proposed mechanisms between air pollution and adverse cardiac effects may also be applicable to human reproduction and IVF failure. These include (i) adverse effect on the autonomic modulation, (ii) systemic inflammation, (iii) oxidative stress and (iv) increased coagulation. Women undergoing a cycle of in vitro fertilization (IVF) represent a unique population for studying the effects of air quality on reproduction since they are generally subfertile, and therefore potentially more susceptible to environmental influences, similar to the people with underlying cardiovascular disease risk factors who experience events during periods of lesser air quality. Most of the key events in the IVF reproductive cycle are timed and triggered by the care giver, so an exact period of exposure can be determined, which is difficult for spontaneous reproduction where the time of ovulation and conception can only be roughly estimated. Determining the exact period of exposure can be critical in determining teratologic effects as the example of thalidomide demonstrates (i.e. only fetuses exposed 34-50 days after the last menstrual period experienced skeletal abnormalities) (Kajii et al., 1973). Gametes and embryos are also uniquely exposed to ambient air during the IVF of oocytes and culture of embryos prior to their transfer to the uterus (Cohen et al., 1997). Finally, much of the relevant data on the outcome of an IVF cycle in the USA including dates and outcomes are prospectively collected and reported by participating IVF programs to the Centers for Disease Control (CDC) as mandated by the federal government (Anonymous, 2007).

The Environmental Protection Agency (EPA) monitors six criteria air pollutants [carbon monoxide, lead, nitrogen dioxide $\left(\mathrm{NO}_{2}\right)$, ozone $\left(\mathrm{O}_{3}\right)$, sulfur dioxide $\left(\mathrm{SO}_{2}\right)$ and particulate matter $(\mathrm{PM})$ ] through a network of nationwide monitors (US Environmental Protection Agency, 2004). PM is composed of extremely small particles and liquid droplets, including acids, such as nitrates and sulfates, organic chemicals, metals and soil/dust particles. Smaller particles, especially particles that are $<10 \mathrm{~mm}$ in diameter $\left(\mathrm{PM}_{10}\right)$ are more likely to escape the defenses of the respiratory tract and travel farther into the lung to act locally or systemically. These small particles and ozone have been shown to be particularly deleterious to human health.

A recent smaller study from Sao Paulo in Brazil found an increased chance of pregnancy loss after both IVF and spontaneous conception in those exposed to the highest quartile of $\mathrm{PM}_{10}$ concentrations during the follicular phase (other pollutants were not examined), supporting both a critical period of exposure and harmful effects on human reproduction (Perin et al., 2009). We hypothesized that worsening air quality as determined by increased concentrations of the criteria pollutants in the ambient environment of women undergoing IVF would be associated with decreased pregnancy and live birth rates.

\section{Materials and Methods}

We examined the outcomes of the first cycle of 7403 female patients undergoing IVF from three centers: Penn State College of Medicine in
Hershey, PA, USA; Shady Grove Fertility in Rockville, MD, USA and Columbia University College of Physicians and Surgeons in New York, NY, USA, for a 7-year period from 2000 to 2007. The timeline and events of an IVF cycle and the mean duration in days are depicted in Fig. I.

\section{Subjects}

This protocol was approved by the Investigational Review Boards at Columbia University and Penn State (which also served as the IRB for Shady Grove Fertility). We used de-identified data and only evaluated the first IVF cycle results of that couple at our centers in order to avoid the confounding that analysis of multiple cycles in the same individual elicits. Baseline characteristics of study subjects are reported in Table I.

\section{Home and IVF clinic site geocodes}

Patient home zip codes were obtained, and the coordinates (latitudes; longitudes) of the centroid of each zip code were assigned according to the US Census 2000 Federal Information Processing Standards (US Census Bureau, 2008). The coordinates of IVF clinical centers were geocoded using ArcView (Redlands, CA, USA).

\section{Air pollutant concentrations}

All ambient criteria air pollutant concentration data recorded at monitors operating in the contiguous USA during the study period (2000-2007) were obtained from the US EPA (Air Quality System, 2007). The data included the longitude and latitude of each monitor. The data were cleaned and then used to fit national-scale, log-normal kriging with a spherical model for spatial interpolations to produce geocoded locationspecific daily mean concentrations of criteria pollutants $\left(\mathrm{PM}_{2.5}, \mathrm{PM}_{10}\right.$, $\mathrm{SO}_{2}, \mathrm{NO}_{2}$ and $\mathrm{O}_{3}$ ) at the patient's home locations and IVF clinic centers for the entire study period (Liao et al., 2006, 2007; Whitsel et al., 2006). From these daily criteria pollutants concentration data, the daily concentrations of $\mathrm{PM}_{2.5}, \mathrm{PM}_{10}, \mathrm{SO}_{2}, \mathrm{NO}_{2}$ and $\mathrm{O}_{3}$ were calculated for each patient during the entire IVF cycle and pregnancy (Table II) and used to estimate the exposure matrix. We did not perform spatial interpolations on carbon monoxide as it is considered a local pollutant, or on lead since our geographic information system (GIS) models for this pollutant have not been validated in other studies (Whitsel et al., 2006).

\section{Statistical analysis}

We did not perform a formal power analysis to determine our sample size, as we had no adequate study performed in a human population to use as a model. On the basis of numbers used for mortality studies and our best estimate, we sought a preliminary sample size between 5000 and 10000 unique individual cycles to address our hypothesis. Major patient characteristics were summarized as means, SDs and proportions. Pregnancy outcomes were binary (yes/no), including serum determination of pregnancy status $\sim 14$ days after embryo transfer, detection of intrauterine pregnancy (IUP) by ultrasound, and live birth. Using negative binomial estimation, we also examined the number of oocytes retrieved and the number of embryos transferred to examine, respectively, possible gamete specific or embryo specific air pollution effects. The exposure matrix for each pollutant was analyzed as a continuous variable. Logistic regression models were used to assess the associations between exposures to criteria pollutants and IVF pregnancy outcomes, and results were expressed as odds ratios (ORs) and $95 \%$ confidence intervals (Cls) associated with I SD increment of each pollutant calculated from the daily pollutant concentrations over the entire study period anchored on the IVF centers $\left(10\right.$ and $8 \mu \mathrm{g} / \mathrm{m}^{3}$ for $\mathrm{PM}_{10}$ and $\mathrm{PM}_{2.5}$, respectively, and $0.03,0.01$ and $0.02 \mathrm{ppm}$ for $\mathrm{SO}_{2}, \mathrm{NO}_{2}$ and $\mathrm{O}_{3}$, respectively), so that the strength of association for each different pollutant could be 


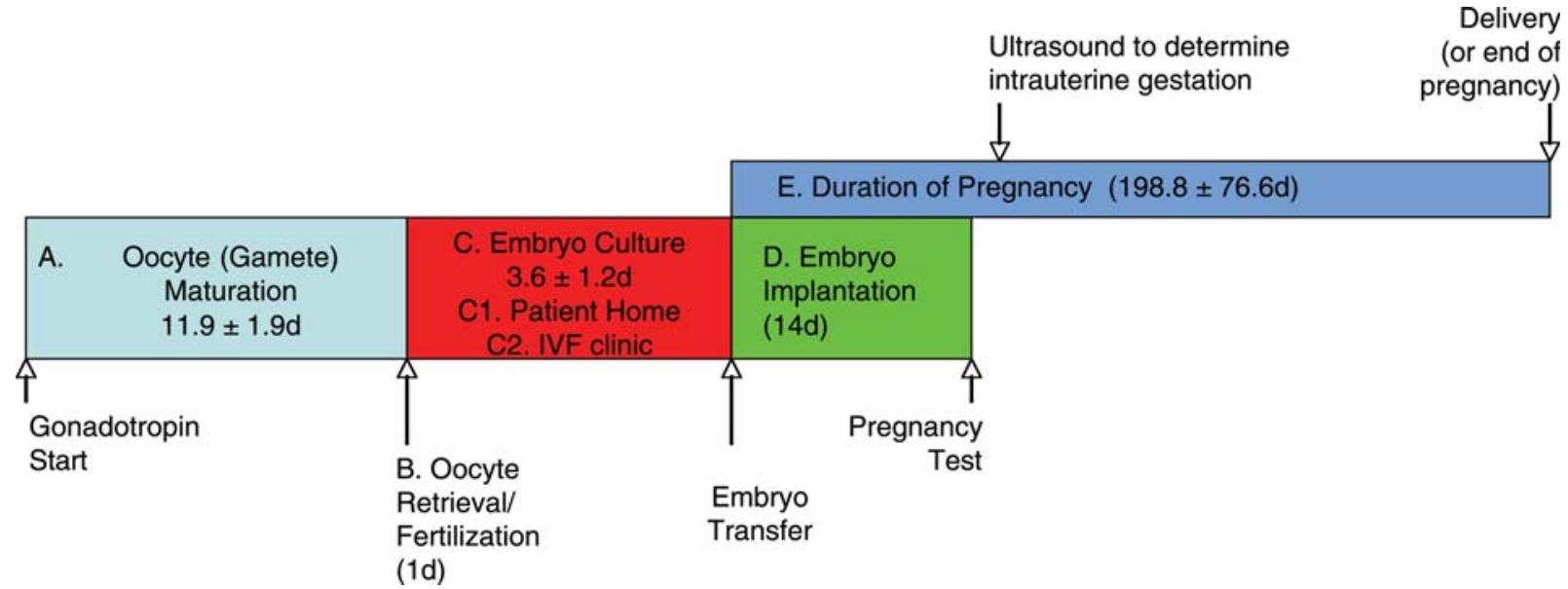

Figure I Timeline of an IVF cycle from start of medications to induce ovulation to the end of pregnancy.

The varying periods of air quality exposure were calculated as follows: (A) average daily concentration at the patient's home from medication start with gonadotrophins to oocyte retrieval, (B) daily concentration on the date of retrieval and oocyte fertilization at the IVF clinic, (CI) average daily concentration at the patient's home from oocyte retrieval to embryo transfer, (C2) average daily concentration at the IVF clinic from oocyte retrieval to embryo transfer, (D) average daily concentration at the patient's home from embryo transfer to pregnancy test. This was set at 14 days. (E) Average daily concentration at the patient's home from embryo transfer until the end of pregnancy. Ultrasound to determine the location and presence of the pregnancy was performed $2-4$ weeks after embryo transfer.

Table I Characteristics of study population from three IVF centers.

\begin{tabular}{|c|c|c|}
\hline & $\begin{array}{l}\text { Number of } \\
\text { patients }\end{array}$ & $\begin{array}{l}\text { Mean } \\
\text { (SD) or \% }\end{array}$ \\
\hline Patient age (years) & 7403 & $35.0(4.5)$ \\
\hline Number of oocytes retrieved & 7394 & I4.3(8.0) \\
\hline Number of embryos transferred & 6982 & $2.4(1.0)$ \\
\hline $\begin{array}{l}\text { Pregnancy, i.e. positive pregnancy } \\
\text { test (\% among those starting IVF } \\
\text { cycle) }\end{array}$ & 3798 & $51.3 \%$ \\
\hline $\begin{array}{l}\text { Intrauterine pregnancy (IUP), i.e. } \\
\text { gestational sac visualized by } \\
\text { ultrasound exam (\% among those } \\
\text { starting IVF cycle) }\end{array}$ & 3250 & $43.9 \%$ \\
\hline $\begin{array}{l}\text { Pregnancy with live birth (\% among } \\
\text { those starting IVF cycle) }\end{array}$ & 2672 & $36.1 \%$ \\
\hline
\end{tabular}

compared. Two types of models were used: single-pollutant models and multi-pollutants models. In the single-pollutant models, each pollutant was entered into the models individually. The multi-pollutants models were employed because the pollutants are interrelated. All statistical models were adjusted for patient's age, IVF center and the year and season of oocyte retrieval. We did not correct for current or past smoking history (which was unavailable in the database), prior IVF cycles in other centers or infertility diagnosis.

\section{Results}

Baseline characteristics of the subjects and their cycles are found in Table I. Mean concentrations for the pollutants did not vary significantly among the time segments of an IVF cycle (Table II). We noted a consistent adverse effect of increasing concentrations of $\mathrm{NO}_{2}$ on the odds of live birth at all time segments in an IVF cycle (Table III), at home and at the IVF lab (Fig. 2), with the largest effect size in the time period from embryo transfer to determination of pregnancy $(O R=0.76,95 \% \mathrm{Cl} 0.66-0.86)$, although the time period from embryo transfer to the date of live birth was marginally significant $(P=0.07)$. No significant effects were identified for $\mathrm{SO}_{2}$, although outcomes were consistently poorer with increasing $\mathrm{SO}_{2}$ exposure, and this trend was nearly significant for IUP rates according to $\mathrm{SO}_{2}$ concentration at the IVF clinic during the period of embryo culture (data not shown). The effects of ozone were bidirectional. Increasing levels of ozone during the period of oocyte maturation were associated with increased chance for a live birth $(P=0.02)$, whereas after embryo transfer it was associated with a significantly decreased odds of live birth $(P=0.002)$. To place the effects of I SD of the air pollutants in context, we noted in our population that a I year increase in age was associated with a decreased chance of pregnancy (OR 0.91, 95\% Cl 0.90-0.92).

Increasing $\mathrm{PM}_{10}$ concentrations had no effect on IVF pregnancy outcomes. There was a significant adverse effect on conception and the chance for an IUP associated with increasing concentration of $\mathrm{PM}_{2.5}$ at the IVF clinic during the period of embryo culture, although this trend was not statistically significant for live birth outcomes (Fig. 2). As for the live birth outcome, there is no clear pattern of a consistent association of $\mathrm{PM}_{2.5}$ and live birth at all time segments in an IVF cycle (Table III). There were no significant associations between pregnancy and live birth with $\mathrm{SO}_{2}$ or $\mathrm{PM}_{10}$ at the IVF lab during the period of embryo culture, nor did we note significant associations between $\mathrm{PM}_{10}$ or $\mathrm{PM}_{2.5}$ at the patient home and these outcomes during the same period (data not shown). We repeated all models by grouping exposures into quartiles and deciles in order to detect the shape of 
Table II Distribution of air pollution variables (data are presented as mean and SD).

\begin{tabular}{|c|c|c|c|c|c|}
\hline & $\begin{array}{l}\text { PM } 2.5 \text { exposure } \\
\left(\mu g / \mathrm{m}^{3}\right)\end{array}$ & $\begin{array}{l}\text { PM } 10 \text { exposure } \\
\left(\mu g / \mathrm{m}^{3}\right)\end{array}$ & $\begin{array}{l}\mathrm{SO}_{2} \text { exposure } \\
(\mathrm{ppm})\end{array}$ & $\begin{array}{l}\mathrm{NO}_{2} \text { exposure } \\
(\mathrm{ppm})\end{array}$ & $\begin{array}{l}\mathrm{O}_{3} \text { exposure } \\
(\mathrm{ppm}) \text { 8-h } \\
\text { rolling average }\end{array}$ \\
\hline $\begin{array}{l}\text { A. Average daily concentration from medication } \\
\text { start to oocyte retrieval (patient home) }\end{array}$ & I $4.08(4.17)$ & $23.80(5.15)$ & $0.059(0.022)$ & $0.019(0.0058)$ & $0.038(0.014)$ \\
\hline $\begin{array}{l}\text { B. Daily concentration on the date of retrieval } \\
\text { (IVF clinic) }\end{array}$ & |4.45 (7.8I) & $23.93(10.17)$ & $0.063(0.030)$ & $0.019(0.008)$ & $0.038(0.018)$ \\
\hline $\begin{array}{l}\mathrm{Cl} \text {. Average daily concentration from oocyte } \\
\text { retrieval to embryo transfer (patient home) }\end{array}$ & 14.12 (5.77) & $24.10(7.59)$ & $0.059(0.025)$ & $0.019(0.007)$ & $0.038(0.015)$ \\
\hline $\begin{array}{l}\text { C2. Average daily concentration from oocyte } \\
\text { retrieval to embryo transfer (IVF clinic) }\end{array}$ & | 4.35 (5.77) & $23.94(7.56)$ & $0.063(0.025)$ & $0.019(0.007)$ & $0.038(0.015)$ \\
\hline $\begin{array}{l}\text { D. Average daily concentration from embryo } \\
\text { transfer to pregnancy test ( } 14 \text { days) (patient home) }\end{array}$ & I4.17 (4.08) & $24.06(4.95)$ & $0.059(0.022)$ & $0.019(0.006)$ & $0.038(0.014)$ \\
\hline $\begin{array}{l}\text { E. Average daily concentration from embryo transfer } \\
\text { to pregnancy outcome date }\end{array}$ & |4.0| (1.96) & $23.85(2.52)$ & $0.057(0.012)$ & $0.018(0.004)$ & $0.037(0.009)$ \\
\hline
\end{tabular}

Table III OR of live birth (with $95 \% \mathrm{Cl}$ ) per unit change in particulate matter $\left(\mathrm{PM}_{2.5}\right.$ and $\left.\mathrm{PM}_{10}\right), \mathrm{NO}_{2}, \mathrm{SO}_{2}$ and $\mathrm{O}_{3}$ air concentration by IVF cycle interval at patient home.

\begin{tabular}{|c|c|c|c|c|c|}
\hline & $\begin{array}{l}\text { Per } 8 \mu \mathrm{g} / \mathrm{m}^{3} \\
\text { increase } \mathrm{PM}_{2.5}\end{array}$ & $\begin{array}{l}\text { Per } 10 \mu g / m^{3} \\
\text { increase } P M_{10}\end{array}$ & $\begin{array}{l}\text { Per } 0.03 \text { ppm } \\
\text { increase } \mathrm{SO}_{2}\end{array}$ & $\begin{array}{l}\text { Per } 0.01 \text { ppm } \\
\text { increase } \mathrm{NO}_{2}\end{array}$ & $\begin{array}{l}\text { Per } 0.02 \mathrm{ppm} \\
\text { increase } \mathrm{O}_{3}\end{array}$ \\
\hline $\begin{array}{l}\text { A. Average daily concentration from medication start } \\
\text { to oocyte retrieval }\end{array}$ & $1.03(0.91-1.16)$ & $1.08(0.98-1.18)$ & $1.00(0.91-1.10)$ & $0.80(0.7|-0.9|)$ & $1.26(1.10-1.44)$ \\
\hline $\begin{array}{l}\mathrm{Cl} \text {. Average daily concentration from oocyte } \\
\text { retrieval to embryo transfer }\end{array}$ & $0.96(0.89-1.04)$ & $1.00(0.93-1.07)$ & $0.94(0.87-1.02)$ & $0.87(0.79-0.96)$ & $1.06(0.96-1.18)$ \\
\hline $\begin{array}{l}\text { D. Average daily concentration from embryo transfer } \\
\text { to pregnancy test ( } 14 \text { days) }\end{array}$ & $1.00(0.89-1.12)$ & $1.05(0.94-1.16)$ & $0.94(0.86-1.04)$ & $0.76(0.66-0.86)$ & $1.23(1.07-1.4 \mathrm{I})$ \\
\hline $\begin{array}{l}\text { E. Average daily concentration from embryo transfer } \\
\text { to the date of live birth }\end{array}$ & $0.82(0.55-1.23)$ & $0.76(0.53-1.09)$ & $0.96(0.73-1.27)$ & $0.76(0.56-1.02)$ & $0.62(0.48-0.8 \mathrm{I})$ \\
\hline
\end{tabular}

associations. In these models, we did not detect any significant deviation of a linear relationship between the exposures and the IVF outcomes (data not shown). We also used negative binomial estimation to analyze the exposure matrix in association with the number of oocytes retrieved (as a possible gamete specific air pollution effect) and the number of embryos transferred. None of the pollutants in the exposure matrix had a statistically significant effect (data not shown).

We looked at the correlation between pollutants during the period from retrieval to transfer as that is the period when mother and embryos were separated. All were significantly correlated, the strongest was between particles of varying diameter $(P<0.0 \mathrm{I})$, the weakest between $\mathrm{PM}_{10}$ and $\mathrm{SO}_{2}(P<0.00 \mathrm{I})$ (Table IV). We created a series of two pollutant models to control for $\mathrm{NO}_{2}$ and $\mathrm{O}_{3}$ during the period from retrieval to transfer at the IVF lab on pregnancy or live birth (Table $V$ ) in order to identify the independent effects of these two gaseous pollutants. We choose these two pollutants in the multi-pollutants models because they showed most consistent associations with various IVF outcomes measures in the single-pollutant models. For the same reason, we choose to model the exposures during the period from retrieval to transfer, and modeled the exposures to these two pollutants at the IVF lab (instead of the patient's home locations). The choice of IVF lab-level exposures was also based on the biological plausibility of embryos been exposed to environmental pollutants during the in vitro incubation period. After controlling for $\mathrm{O}_{3}, \mathrm{NO}_{2}$ continued to be significantly associated with IVF failure, including failure to achieve pregnancy, IUP and live birth. After controlling for $\mathrm{NO}_{2}, \mathrm{O}_{3}$ was no longer significantly associated with IVF failure.

\section{Discussion}

Fluctuations in criteria air pollutants have varying and complex associations with assisted reproduction outcomes in an infertile population. We have observed the expected adverse association between increasing levels of select criteria pollutants, most clearly and consistently with $\mathrm{NO}_{2}$, and odds of pregnancy after IVF. In contrast, from the single-pollutant models, we noted unexpected positive associations between ozone levels and live birth rates at the patient address prior to embryo culture and after embryo transfer, followed by the anticipated negative association during the ongoing pregnancy. Our modeling suggests that the paradoxical findings with $\mathrm{O}_{3}$ during the 

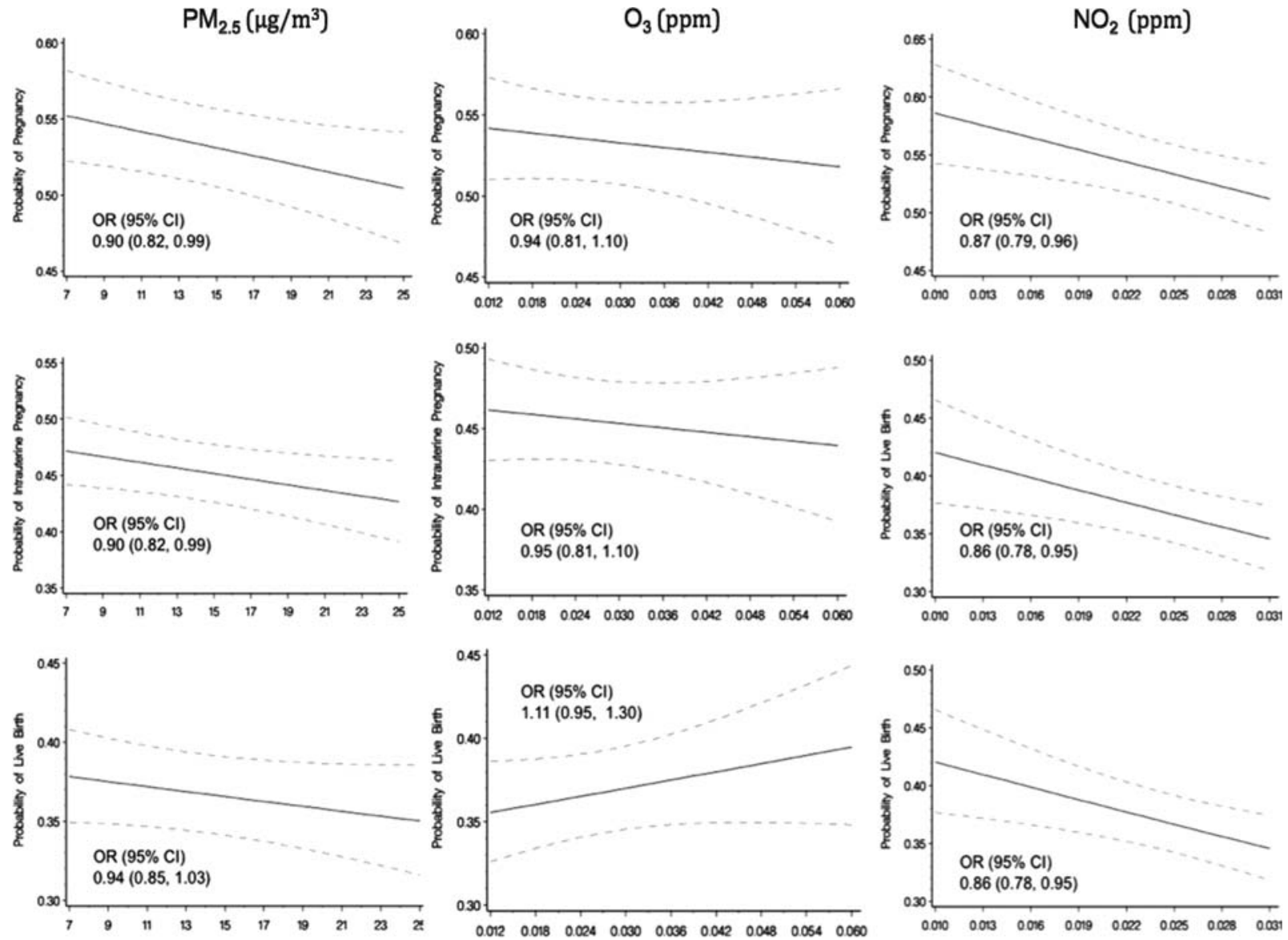

Figure 2 Pregnancy and live birth regression lines and $95 \% \mathrm{Cl}$ lines with concentration of three pollutants $\left(\mathrm{PM}_{2.5}, \mathrm{O}_{3}\right.$ and $\left.\mathrm{NO}_{2}\right)$ at the IVF lab site from retrieval till transfer ( $x$-axis) with the probability of the three events ( $y$-axis), pregnancy as determined by serum pregnancy test, IUP as determined by ultrasound, and live birth. This is a single-pollutant model adjusted for confounders.

Table IV Pearson's correlation coefficients correlation of pollutants during the retrieval to transfer at clinical sites $(n=6492)$.

\begin{tabular}{|c|c|c|c|c|c|}
\hline & $\mathrm{PM}_{2.5}$ & $\mathrm{PM}_{10}$ & $\mathrm{SO}_{2}$ & $\mathrm{NO}_{2}$ & $\mathrm{O}_{3}$ \\
\hline \multirow{2}{*}{$\mathrm{PM}_{2.5}$} & 1.00 & 0.86 & 0.17 & 0.19 & 0.46 \\
\hline & & $<0.001$ & $<0.001$ & $<0.001$ & $<0.001$ \\
\hline \multirow{2}{*}{$\mathrm{PM}_{10}$} & 0.86 & 1.00 & 0.09 & 0.18 & 0.54 \\
\hline & $<0.001$ & & $<0.00$ I & $<0.001$ & $<0.001$ \\
\hline \multirow[t]{2}{*}{$\mathrm{SO}_{2}$} & 0.17 & 0.09 & 1.00 & 0.74 & -0.40 \\
\hline & $<0.001$ & $<0.001$ & & $<0.001$ & $<0.001$ \\
\hline \multirow[t]{2}{*}{$\mathrm{NO}_{2}$} & 0.19 & 0.18 & 0.74 & 1.00 & -0.44 \\
\hline & $<0.001$ & $<0.001$ & $<0.001$ & & $<0.001$ \\
\hline \multirow[t]{2}{*}{$\mathrm{O}_{3}$} & 0.46 & 0.54 & -0.40 & -0.44 & 1.00 \\
\hline & $<0.001$ & $<0.001$ & $<0.001$ & $<0.001$ & \\
\hline
\end{tabular}

peri-conceptional period may be due to the confounding by $\mathrm{NO}_{2}$, i.e. that they are negatively correlated such that high $\mathrm{O}_{3}$ is indicative of lower $\mathrm{NO}_{2}$, and thus the favorable association with latter improves pregnancy outcomes. This confounded association of $\mathrm{O}_{3}$ is further substantiated from the multi-pollutants models, where the 'protective' effects of $\mathrm{O}_{3}$ from single-pollutant models were diminished after controlling for $\mathrm{NO}_{2}$. However, the adverse $\mathrm{NO}_{2}$ effects on pregnancy outcome remain significant even after controlling for $\mathrm{O}_{3}$ in the multipollutants models. These findings underscore that criteria pollutants may have select effects at certain junctures of the IVF cycle (Perin et al., 2009). Finally, some pollutants such as $\mathrm{SO}_{2}$ or $\mathrm{PM}_{10}$ have no discernible effects on pregnancy in this model. The absolute effects of air quality changes have a clinically significant impact in pregnancy outcomes (10-15\% changes per I SD fluctuations in pollutants). This represents perhaps the clearest evidence to date of the potential impact of air pollution on conception and live birth in human reproduction.

The strength of our study includes the selection of an IVF population, allowing us to accurately time the key events in ovulation and fertilization. This is also a large sample size from a representative urban, suburban and rural population in the USA. Finally, the study design links data (both air quality by the US EPA and IVF results by the US Centers for Disease Control) that were collected prospectively and monitored in compliance with federal guidelines. The GIS-based estimation of ambient daily air quality using the EPA air quality data 
Table V Two pollutants $\left(\mathrm{NO}_{2}\right.$ and $\left.\mathrm{O}_{3}\right)$ model during retrieval to transfer at clinical IVF site on IUP by ultrasound or live birth

\begin{tabular}{|c|c|c|c|c|c|c|}
\hline Response variable & $\begin{array}{l}\text { Total } \\
\text { number }\end{array}$ & $\begin{array}{l}\text { Positive } \\
\text { outcome }\end{array}$ & Percentage & $\begin{array}{l}\text { Independent } \\
\text { variable }\end{array}$ & OR (95\% Cl) & $P$-value \\
\hline \multirow[t]{3}{*}{ Pregnancy (as defined by a positive serum pregnancy tests) } & 6942 & 3755 & 54.1 & $\mathrm{NO}_{2}$ : IVF lab & $0.86(0.78-0.95)$ & 0.003 \\
\hline & & & & $\mathrm{O}_{3}$ : IVF lab & $0.95(0.85-1.05)$ & 0.276 \\
\hline & & & & Age & $0.91(0.90-0.92)$ & $<0.001$ \\
\hline \multirow{3}{*}{$\begin{array}{l}\text { Intrauterine pregnancy (as defined by an intrauterine } \\
\text { gestational sac visualized by ultrasound) }\end{array}$} & 6942 & 3220 & 46.4 & $\mathrm{NO}_{2}$ : IVF lab & $0.84(0.76-0.93)$ & 0.001 \\
\hline & & & & $\mathrm{O}_{3}:$ IVF lab & $0.95(0.85-1.05)$ & 0.274 \\
\hline & & & & Age & $0.91(0.90-0.92)$ & $<0.001$ \\
\hline \multirow[t]{3}{*}{ Live birth } & 6922 & 2645 & 38.2 & $\mathrm{NO}_{2}:$ IVF Lab & $0.86(0.78-0.96)$ & 0.006 \\
\hline & & & & $\mathrm{O}_{3}:$ IVF Lab & $1.05(0.95-1.17)$ & 0.316 \\
\hline & & & & Age & $0.89(0.88-0.90)$ & $<0.001$ \\
\hline
\end{tabular}

has been validated empirically (Liao et al., 2006, 2007), and used in population-based studies of air quality effects on cardiac responses (Liao et al., 2009; Whitsel et al., 2009). Our study has also focused on the primary outcome of infertility treatment, i.e. live birth, and not on surrogate markers of fertility such as gamete quality or genetic instability (Somers et al., 2002; Sokol et al., 2006; Yauk et al., 2008), although our data suggest a preconceptional effect possibly mediated through gametes.

Our study has several limitations. Though similar, IVF cycle protocols were not standardized among the centers. We did control for the center, the year and season of the oocyte retrieval and the age of the patient, which are the most important factors associated with success rates (Anonymous, 2007). Our sample size is robust, but it is possible that with a larger sample size, we would have detected significant associations with other pollutants, such as $\mathrm{PM}_{10}$ and $\mathrm{SO}_{2}$. We lack data on other pollutants not measured by the air monitors, or whether the patient or her husband smoked (although it is the routine policy of our programs to recommend and encourage smoking cessation during the IVF cycle). We have little information on the male partner, obviously equally vital to reproductive success, and our study lacks data on semen parameters on the day of fertilization. We did not examine the confounding role of other infertility diagnoses due to concerns about the accuracy of the reported diagnosis (Molinaro et al., 2009), and the problem of multiple analyses from a limited data set.

We do not have precise records of the patient's or her partner's movements during an IVF cycle and how much time she or he spent at their home address or were outside exposed to ambient air. A recent study of pregnant women found that spatially resolved land-use regression models for the postal home zip code of the patient and ambient monitoring data were significantly, though moderately correlated ( $R=0.49$ for nitric oxide), supporting the use of these models in epidemiological studies (Nethery et al., 2008). We also do not know if the air quality of a controlled environment such as inside an IVF lab (or incubator) correlates with local ambient levels (Boone et al., 1999), which were the primary exposures we analyzed in this report.

We did not find a specific threshold at which declining air quality triggered an adverse pregnancy rate, unlike the study of $\mathrm{PM}_{10}$ from
Brazil (Perin et al., 2009); rather, we noted a continuous effect. Our mean air quality is better than that reported in other studies of adverse reproductive outcomes from more polluted areas (e.g. mean pregnancy exposure of $\mathrm{PM}_{10}$ of $34 \mu \mathrm{g} / \mathrm{m}^{2}$ and $\mathrm{PM}_{2.5}$ of $34 \mu \mathrm{g} / \mathrm{m}^{2}$ during 2002-2003 in the Los Angeles basin; Ritz et al., 2007), but comparable to that of studies showing similar adverse reproductive effects from areas of lower air pollution levels $\left(\mathrm{PM}_{10}\right.$ of $22.3 \mu \mathrm{g} / \mathrm{m}^{2}$ and $\mathrm{PM}_{2.5}$ of II.9 $\mu \mathrm{g} / \mathrm{m}^{2}$ for Connecticut and Massachusetts during 1999-2002; Bell et al., 2007).

We noted the most consistent negative associations and pregnancy after IVF with nitrogen dioxide. This gas is produced by combustion at high temperatures and originates primarily from motor vehicles, especially trucks. Indoors common sources are also from combustion such as gas stoves, vented appliances with defective installations, welding and tobacco smoke. Exposure has been associated primarily with respiratory symptoms and toxicity. Data linking it to mortality are not conclusive from long-term exposure studies, unlike other criteria pollutants. It is possible that women undergoing IVF are more exposed to $\mathrm{NO}_{2}$ during a cycle given more frequent commuting to and from medical care because of monitoring visits and procedures. As our data indicate, there are also complex relationships between nitrogen dioxide, PM, and ozone in the ambient air (all of which were associated with reproductive outcomes in our study), making it difficult to single out one of these as the cause (World Health Organization, 2003; Air Quality System, 2007). Air monitors may be less accurate for spatially heterogeneous air pollutants such as nitrogen oxides which may have much higher concentrations close to the source (Ritz and Wilhelm, 2008).

We noted an association between small particle concentration and IVF failure only during the period of oocyte fertilization and embryo culture at the IVF lab and not at the patient address, implying this may be an effect related to exposure to ambient air or some lesser version of it in the IVF lab. Our effect size $(\sim 10 \%)$ of I SD change in $\mathrm{PM}_{2.5}$ (and the other pollutants) on reproduction is similar to that on mortality. In mouse reproductive studies, adverse air quality effects are effectively prevented through the use of high efficiency particulate air filtration (Somers et al., 2004). Air filtrations systems are common in our IVF labs, which are tightly controlled environments 
(Boone et al., 1999). Fine air particles are composed of a variety of compounds, including non-organic (sulfate, nitrate, ammonium and hydrogen ions, metals) and organic (polycyclic aromatic hydrocarbons), that can circulate systematically and influence gamete activation, fertilization and embryo development.

In summary, we have shown that exposure to a range of air pollutants has a significant effect of modest magnitude (equivalent to I-2 years of increased maternal age per I SD variation) on the chance for conception after a cycle of IVF. These effects may not be applicable to the larger fertile population who conceives spontaneously without medical assistance or potential in vitro exposure of gametes and embryos to ambient air. However, as fertility rates fall in developed countries, assisted reproduction is responsible for a larger percentage of the birth rate. In Denmark, it is estimated that up to $7 \%$ of births now result from infertility treatment (Sobotka et al., 2008), and a 3-month study in Massachusetts in 2005 showed 6.1\% of live births were from infertility treatment (Lu et al., 2008). Thus, this remains an important health issue, even if only relevant to assisted reproduction. We note also that IVF success rates in the USA have consistently improved, since annual reporting of results was instituted. These improving results may reflect innovative technology in the IVF arena (Anonymous, 2007), but may also partially be influenced by improving air quality in the USA (Vandenberg 2005; Pope et al., 2009). Our findings may therefore hold particular relevance to the developing world where utilization of IVF is growing exponentially, as the air quality of their urban areas progressively declines. Further studies with more detailed monitoring of air quality and exposure during reproduction, and of potential mechanisms are indicated.

\section{Authors' roles}

All authors were involved in the conception, design, acquisition of data and its analysis, revising the article critically and final approval of the submitted version.

\section{Funding}

This project is funded, in part, under a grant with the Pennsylvania Department of Health using Tobacco Settlement Funds. The Department specifically disclaims responsibility for any analyses, interpretations or conclusions.

\section{References}

Air Quality System. United States Environmental Protection Agency. 2007. http://www.epa.gov/ttn/airs/airsaqs/ (I8 November 2009, date last accessed).

Anonymous. Assisted reproductive technology in the United States: 2001 results generated from the American Society for Reproductive Medicine/Society for Assisted Reproductive Technology registry. Fertil Steril 2007;87:1253-1266.

Anonymous. Smoking and infertility. Fertil Steril 2008;90:S254-S259.

Bell ML, Ebisu K, Belanger K. Ambient air pollution and low birthweight in Connecticut and Massachusetts. Environ Health Perspect 2007; II5: III8-1124.

Boone WR, Johnson JE, Locke AJ, Crane MMT, Price TM. Control of air quality in an assisted reproductive technology laboratory. Fertil Steril 1999;7I:150-154.
Cohen J, Gilligan A, Esposito W, Schimmel T, Dale B. Ambient air and its potential effects on conception in vitro. Hum Reprod 1997; I 2: 1742- 1749.

Feichtinger W, Papalambrou K, Poehl M, Krischker U, Neumann K. Smoking and in vitro fertilization: a meta-analysis. J Assist Reprod Genet 1997; 14:596-599.

Goldberg MS, Burnett RT, Bailar JC III, Brook J, Bonvalot Y, Tamblyn R, Singh $R$, Valois MF, Vincent $R$. The association between daily mortality and ambient air particle pollution in Montreal, Quebec. 2. Cause-specific mortality. Environ Res 200I;86:26-36.

Hackley B, Feinstein A, Dixon J. Air pollution: impact on maternal and perinatal health. J Midwifery Women's Health 2007;52:435-443.

Kajii T, Kida M, Takahashi K. The effect of thalidomide intake during 1 I 3 human pregnancies. Teratology 1973;8:163-166.

Lee BE, Ha EH, Park HS, Kim YJ, Hong YC, Kim H, Lee JT. Exposure to air pollution during different gestational phases contributes to risks of low birthweight. Hum Reprod 2003; 18:638-643.

Liao D, Peuquet DJ, Duan Y, Whitsel EA, Dou J, Smith RL, Lin HM, Chen JC, Heiss G. GIS approaches for the estimation of residential-level ambient PM concentrations. Environ Health Perspect 2006; I I 4: |374-1380.

Liao D, Peuquet DJ, Lin HM, Duan Y, Whitsel EA, Smith RL, Heiss G. National kriging exposure estimation. Environ Health Perspect 2007; I I5:A338-A339.

Liao D, Whitsel EA, Duan Y, Lin HM, Quibrera PM, Smith R, Peuquet DJ, Prineas RJ, Zhang ZM, Anderson G. Ambient particulate air pollution and ectopy - the environmental epidemiology of arrhythmogenesis in Women's Health Initiative Study, 1999-2004. J Toxicol Environ Health 2009;72:30-38.

Lu E, Barfield WD, Wilber N, Diop H, Manning SE, Fogerty S. Surveillance of births conceived with various infertility therapies in Massachusetts, January-March 2005. Public Health Rep 2008; 1 23: 173- 177.

Molinaro TA, Shauknik A, Lin K, Sammel MD, Barnhart KT. A strict infertility diagnosis has poor correlation with the clinical diagnosis entered into SART. Fertil Steril 2009;92:2088-2090.

Nethery E, Leckie SE, Teschke K, Brauer M. From measures to models: an evaluation of air pollution exposure assessment for epidemiological studies of pregnant women. Occup Environ Med 2008;65:579-586.

Ostro B, Broadwin R, Green S, Feng WY, Lipsett M. Fine particulate air pollution and mortality in nine California counties: results from CALFINE. Environ Health Perspect 2006; I I 4:29-33.

Perin PM, Maluf M, Czeresnia CE, Nicolosi Foltran Januario DA, Nascimento Saldiva PH. Effects of exposure to high levels of particulate air pollution during the follicular phase of the conception cycle on pregnancy outcome in couples undergoing in vitro fertilization and embryo transfer. Fertil Steril 20 10;93:30I-303.

Peters JM, Avol E, Navidi W, London SJ, Gauderman WJ, Lurmann F, Linn WS, Margolis H, Rappaport E, Gong $\mathrm{H}$ et al. A study of twelve Southern California communities with differing levels and types of air pollution. I. Prevalence of respiratory morbidity. Am J Respir Crit Care Med 1999; 159:760-767.

Pope CA III, Dockery DW, Spengler JD, Raizenne ME. Respiratory health and $\mathrm{PM}_{10}$ pollution. A daily time series analysis. Am Rev Respir Dis 1991; 144:668-674.

Pope CA III, Ezzati M, Dockery DW. Fine-particulate air pollution and life expectancy in the United States. N Engl J Med 2009;360:376-386.

Ritz B, Wilhelm M. Ambient air pollution and adverse birth outcomes: methodologic issues in an emerging field. Basic Clin Pharmacol Toxicol 2008; 102:182-190.

Ritz B, Wilhelm M, Hoggatt KJ, Ghosh JK. Ambient air pollution and preterm birth in the environment and pregnancy outcomes study at the University of California, Los Angeles. Am J Epidemiol 2007; 1 66: 1045- 1052. 
Sobotka T, Hansen MA, Pedersen AT, Lutz W, Skakkebaek NE. The contribution of assisted reproduction to completed fertility: an analysis of Danish data. Popul Dev Rev 2008;34:79- I0I.

Sokol RZ, Kraft P, Fowler IM, Mamet R, Kim E, Berhane KT. Exposure to environmental ozone alters semen quality. Environ Health Perspect 2006; I I 4:360-365.

Somers CM, Yauk CL, White PA, Parfett CL, Quinn JS. Air pollution induces heritable DNA mutations. Proc Natl Acad Sci USA 2002;99: I 5904- 15907.

Somers CM, McCarry BE, Malek F, Quinn JS. Reduction of particulate air pollution lowers the risk of heritable mutations in mice. Science 2004; 304: $1008-1010$.

Sram RJ, Binkova B, Dejmek J, Bobak M. Ambient air pollution and pregnancy outcomes: a review of the literature. Environ Health Perspect 2005; I | 3:375-382.

US Census Bureau, Washington, DC. 2008. http://wwwcensusgov/main/ www/cen2000html (I8 November 2009, date last accessed).

US Environmental Protection Agency. US EPA. Air Quality Criteria for Particulate Matter. Final Report, October 2004. 2004, 600/P-99/ 002aF-bF, Vol. II, 539-543.

Vandenberg JJ. The role of air quality management programs in improving public health: a brief synopsis. I Allergy Clin Immunol 2005; II5: 334-336.
Wellenius GA, Schwartz J, Mittleman MA. Air pollution and hospital admissions for ischemic and hemorrhagic stroke among medicare beneficiaries. Stroke 2005;36:2549-2553.

Wellenius GA, Schwartz J, Mittleman MA. Particulate air pollution and hospital admissions for congestive heart failure in seven United States cities. Am J Cardiol 2006;97:404-408.

Whitsel EA, Quibrera PM, Smith RL, Catellier DJ, Liao D, Henley AC, Heiss G. Accuracy of commercial geocoding: assessment and implications. Epidemiol Perspect Innov 2006;3:8.

Whitsel EA, Quibrera PM, Christ SL, Liao D, Prineas RJ, Anderson GL, Heiss G. Heart rate variability, ambient particulate matter air pollution, and glucose homeostasis: the environmental epidemiology of arrhythmogenesis in the women's health initiative. Am J Epidemiol 2009; 169:693-703.

World Health Organization. Health Aspects of Air Pollution with Particulate Matter, Ozone and Nitrogen Dioxide. 2003. http://www.euro.who.int/ document/e79097.pdf.

Yauk C, Polyzos A, Rowan-Carroll A, Somers CM, Godschalk RW, Van Schooten FJ, Berndt ML, Pogribny IP, Koturbash I, Williams A et al. Germ-line mutations, DNA damage, and global hypermethylation in mice exposed to particulate air pollution in an urban/industrial location. Proc Natl Acad Sci USA 2008; 105:605-6I0. 